\title{
Involvement of $\beta_{2}$-adrenoceptor-mediated mechanisms in the cardiovascular responses to $\alpha_{1}$ - and $\alpha_{2}-$ adrenoceptor antagonism in conscious, unrestrained, Long Evans and Brattleboro rats
}

\author{
Sheila M. Gardiner \& Terence Bennett \\ Department of Physiology \& Pharmacology, Medical School, Queen's Medical Centre, Nottingham NG7 2UH
}

1 Intra-arterial blood pressures and heart rates were recorded in conscious, unrestrained, Long Evans and Brattleboro rats receiving sequential, continuous administrations of selective $\alpha_{1}$ - (prazosin) and $\alpha_{2}$ - (idazoxan) adrenoceptor antagonists. The same protocols were also run in the presence of ICI 118551 (a selective antagonist of $\boldsymbol{\beta}_{2}$-adrenoceptors).

2 Prazosin and idazoxan caused large, but transient, hypotensions in Long Evans and Brattleboro rats. In the continued presence of both drugs there were marked, intermittent, depressor episodes and tachycardias in both strains of rat.

3 In the presence of low or high doses of ICI 118551 the hypotensive responses to prazosin and idazoxan were markedly reduced in both strains of rat and blood pressures showed little variability, although intermittent tachycardias still occurred.

4 In adrenal-demedullated Long Evans rats, the hypotensive responses to prazosin and idazoxan were attenuated and in the presence of both drugs, blood pressure was relatively steady, although intermittent tachycardias still occurred.

5 In the presence of prazosin and idazoxan, when a depressor episode was not occurring, administration of captopril caused hypotension in Long Evans and Brattleboro rats. In the latter, the reduction in blood pressure was sustained, whereas there was a recovery in blood pressure in Long Evans rats. This recovery was punctuated by depressor episodes, and was abolished by a $V_{1}$-receptor antagonist $\left(\mathrm{d}\left(\mathrm{CH}_{2}\right)_{5} \mathrm{DAVP}\right)$.

6 Long Evans rats given two primed doses of the non-selective $\alpha$-adrenoceptor antagonist, phentolamine, exhibited variation in blood pressure similar to that seen in the presence of prazosin and idazoxan. As in the latter case, blood pressure variability was inhibited by the $\beta_{2}$-adrenoceptor antagonist, ICI 118551.

7 Administration of idazoxan into a lateral ventricle in Long Evans rats receiving phenoxybenzamine intravenously did not cause blood pressure instability. However, intravenous administration of idazoxan in the same animals produced intermittent depressor episodes and tachycardias similar to those seen in the presence of prazosin and idazoxan.

8 The simplest explanation of the results is that $\boldsymbol{\beta}_{2}$-adrenoceptor-mediated depressor mechanisms contribute to the hypotensive responses to $\alpha_{1}-$ and $\alpha_{2}$-adrenoceptor antagonism. Furthermore, in the presence of adequate peripheral $\alpha_{1}$ - and $\alpha_{2}$-adrenoceptor antagonism, blood pressure may be maintained by the renin-angiotensin system and vasopressin (although it is only when the former system has been antagonized that a clear-cut pressor action of vasopressin is apparent). Under these conditions, blood pressure maintenance is interrupted by intermittent depressor episodes that are largely due to adrenal medullary activation.

\section{Introduction}

The cardiovascular sequelae of non-selective $\alpha$-adrenoceptor antagonism are complex. In addition to straightforward inhibition of peripheral postjunc- tional vascular $\alpha$-adrenoceptors, central actions and peripheral prejunctional effects may cause sympathoexcitation, to a greater or lesser extent, depending on 
the drugs used (Kobinger, 1984). Such increased sympathetic efferent activity may elicit renin release $\left(\boldsymbol{\beta}_{1}\right.$-adrenoceptor-mediated; see Keeton \& Campbell, 1981). In the rat, stimulation of the renin-angiotensin system following non-selective $\alpha$-adrenoceptor antagonism may also result from an action of the drug on $\boldsymbol{\alpha}_{2}$-adrenoceptors that normally inhibit renin release (Summers, 1984). Activation of the reninangiotensin system could oppose the loss of neural vasoconstrictor tone. Evidence for such a sequence of events comes from the finding that $\alpha_{1}$-adrenoceptor antagonism in the presence of angiotensin converting enzyme inhibition causes a more severe hypotension than when the renin-angiotensin system is intact (Smith et al., 1981; Goering \& Zimmerman, 1986). It is surprising, then, that the hypotensive effects of the non-selective $\alpha$-adrenoceptor antagonist, phentolamine, are not enhanced by pretreatment with a non-selective $\boldsymbol{\beta}$-adrenoceptor antagonist which inhibits the rise in plasma renin activity (Burnier et al., 1983). The most likely explanation of this finding is that non-selective $\beta$-adrenoceptor antagonism also inhibits a $\boldsymbol{\beta}_{2}$-adrenoceptor-mediated mechanism which was previously contributing to the hypotension (Gomes et al., 1978). Indeed, Gomes et al. (1978) produced evidence that the hypotensive responses to non-selective $\alpha$-adrenoceptor antagonists in conscious rats were largely dependent on $\boldsymbol{\beta}_{2}$-adrenoceptormediated mechanisms. However, there have been no studies of the relative contributions of such mechanisms to the blood pressure (BP) responses to $\alpha_{1}$ - and $\alpha_{2}$ adrenoceptor antagonists in conscious rats.

In the present work we investigated the cardiovascular effects of a selective $\alpha_{1}$-adrenoceptor antagonist (prazosin) followed by a selective $\alpha_{2}$-adrenoceptor antagonist (idazoxan) in the absence, or presence, of the $\boldsymbol{\beta}_{2}$-adrenoceptor-selective antagonist ICI 118551 (Bilski et al., 1983). Since idazoxan readily gains access to the brain (Clifford et al., 1983), we performed these experiments in normal (Long Evans) rats and in rats deficient in hypothalamic and pituitary vasopressin (Brattleboro strain) to determine if there was any evidence that disinhibition of vasopressin release due to central $\alpha_{2}$-adrenoceptor antagonism (Brooks et al., 1986) was contributing to the effects we observed.

In the first series of experiments we found that administration of prazosin caused a marked, but transient fall in systemic arterial BP. In the continued presence of prazosin, administration of idazoxan caused a substantial hypotension, but BP rapidly recovered. However, in the presence of both drugs there were marked, intermittent, depressor episodes, although generally, BP was well-maintained. The initial hypotensive responses to prazosin and idazoxan and the ensuing depressor episodes were substantially reduced in the presence of ICI 118551.

These initial observations raised several questions:
(1) To what extent did the adrenal medullae contribute to the cardiovascular effects of prazosin and idazoxan? Although $\boldsymbol{\beta}_{2}$-adrenoceptor-mediated effects appeared to contribute to the initial hypotensive responses to prazosin and idazoxan, as well as to the BP instability seen in the presence of both drugs, those experiments did not provide information about the relative involvement of the adrenal medulla in the activation of $\boldsymbol{\beta}_{2}$-adrenoceptors. Therefore, we investigated the cardiovascular responses to administration of prazosin and idazoxan in adrenal-demedullated Long Evans rats.

(2) What were the contributions of the reninangiotensin system and, subsequently vasopressin to the maintenance of BP in the presence of prazosin and idazoxan? In the presence of both $\alpha$-adrenoceptor antagonists, when a depressor episode was not occurring, BP was well-maintained in both Long Evans and Brattleboro rats. In order to assess the possible roles of the renin-angiotensin system and vasopressin in the maintenance of BP under these conditions we investigated the cardiovascular effects of the angiotensin converting enzyme inhibitor, captopril, and (in Long Evans rats) an antagonist of the $\mathrm{V}_{1}$-receptor actions of vasopressin $\left(\mathrm{d}\left(\mathrm{CH}_{2}\right)_{5}\right.$ DAVP).

(3) Were these findings peculiar to the combination of prazosin and idazoxan? Although administration of our usual dose of the non-selective $\alpha$-adrenoceptor antagonist, phenoxybenzamine, does not cause BP instability (Winn et al., 1985), this drug is a relatively poor $\alpha_{2}$-adrenoceptor antagonist (Minneman, 1983). Furthermore, while phentolamine can induce some BP instability, the pattern of variation is different from that seen with prazosin and idazoxan (Winn et al., 1985). Therefore, we carried out experiments to determine if sequential dosing with phentolamine or a combination of phenoxybenzamine and idazoxan could induce intermittent depressor episodes.

(4) Were these findings dependent on a central action of idazoxan? As mentioned above, idazoxan readily gains access to the brain when administered peripherally (Clifford et al., 1983). In order to determine if central $\alpha_{2}$-adrenoceptor antagonism was responsible for BP instability (by a mechanism other than disinhibition of vasopressin release, see above), Long Evans rats receiving intravenous phenoxybenzamine (i.e. a relatively selective $\alpha_{1}$-adrenoceptor antagonist that does not gain access to the brain easily) were given idazoxan intracerebroventricularly in a dose sufficient to block central $\alpha_{2}$-adrenoceptor-mediated effects (Brown \& Harland, 1984). While central $\alpha_{2}$-adrenoceptors were still blocked these animals were also given idazoxan intravenously.

Some of these results have been reported to the Physiological Society (Bennett et al., 1986b; Bennett \& Gardiner, 1987a; b). 


\section{Methods}

In all experiments male, Long Evans rats $(380-460 \mathrm{~g})$ were used. In those investigations involving homozygous Brattleboro rats $(320-380 \mathrm{~g})$, they were sex- and age-matched with the Long Evans rats. The basic protocol for all studies was similar (specific experimental details are given below).

Between $06 \mathrm{~h} 00 \mathrm{~min}$ and $07 \mathrm{~h} 30 \mathrm{~min}$ the rats were anaesthetized with a short-acting barbiturate (sodium methohexitone, $60 \mathrm{mg} \mathrm{kg}^{-1}$ intraperitoneally) and catheters were implanted in the common jugular vein (up to 3 separate catheters for drug administrations) and abdominal aorta (via the caudal artery for BP recording) (Gardiner et al., 1980).

At least $5 \mathrm{~h}$ after recovery from anaesthesia, resting BPs were measured by means of a pressure transducer (Bell and Howell type 4-442) with a low volumedisplacement dome connected, via an amplifier (Gould Model 13-4615-50) to an electrostatic recorder (Gould Model ES 1000). Instantaneous heart rate (HR) was derived from the BP recording (Gould Biotach amplifier Model 13-4615-66) and displayed on the recorder. Dynamic testing (Ardill et al., 1967) of this system showed that it was flat to $50 \mathrm{~Hz}$, and hence capable of faithfully recording the full intra-arterial pressure wave up to heart rates of 600 beats min $^{-1}$ (Geddes, 1970). Since this is well in excess of the cardiac frequencies seen in the present study, and since we have shown that pacing the heart up to this frequency does not produce falls in systolic or diastolic BP (Gardiner et al., 1980), then it is likely that the changes in BP we recorded with drug administrations in the present study were real rather than due to a recording artefact or to failure of cardiac output consequent upon drug-induced tachycardias.

An example of an intra-arterial pressure recording is given in Figure 1a. As shown elsewhere (Gardiner \& Bennett, 1986) systolic BP is higher in the abdominal aorta than in the carotid artery (and higher than in most other published recordings, since the latter are usually made with over-damped, rather than criticallydamped systems). We recorded the full pressure waveform rather than the electronically derived mean since the latter variable provides less information (see results).

Intra-arterial BPs and instantaneous HRs were recorded simultaneously on paper (Gould ES 1000) and on FM tape (Racal Store 4). Replaying the tape at high speed on to the recorder made it possible to condense experimental records for illustrative purposes, but all measurements of systolic and diastolic BPs and HRs were made on records played at a speed $\left(20 \mathrm{~mm} \mathrm{~min}^{-1}\right)$ that ensured the average value of the variables was evident during the period of interest.

After a $30 \mathrm{~min}$ period of baseline recordings, the following experiments were performed:

\section{Experiment 1: The effects of sequential administration of prazosin and idazoxan}

Eight Long Evans and 7 Brattleboro rats were used. Prazosin (0.5 $\mathrm{mg} \mathrm{kg}^{-1}$ bolus; $0.8 \mathrm{mg} \mathrm{kg}^{-1} \mathrm{~h}^{-1}$ infusion) was administered for $45 \mathrm{~min}$ after which idazoxan $\left(0.75 \mathrm{mg} \mathrm{kg}^{-1}\right.$ bolus; $1 \mathrm{mg} \mathrm{kg}^{-1} \mathrm{~h}^{-1}$ infusion) was given through a second catheter, while prazosin administration was continued. We also ran control experiments ( $n=4$ in both strains) in which the procedure above was carried out using the drug vehicles alone. Administration of the vehicles produced no systematic changes in BP or HR, although occasionally the bolus injection caused a brief startle response (slight tachycardia $\left(<20\right.$ beats min $\left.^{-1}\right)$ and BP increase $(<10 \mathrm{mmHg}$ ) lasting about $10 \mathrm{~s})$, quite distinct from the drug-mediated effects (see Results).

\section{Experiment 2: The effects of sequential administration of prazosin and idazoxan in the presence of ICI 118551}

Although ICI 118551 is highly selective for $\boldsymbol{\beta}_{2}$-adrenoceptors, published data in other species (Bilski et al., 1983) and our own preliminary experiments in conscious rats indicated that a dose of this drug sufficient to cause maximal antagonism of peripheral $\beta_{2}$-adrenoceptors could exert effects on $\boldsymbol{\beta}_{1}$-adrenoceptors. We elected, therefore, to run two experimental protocols with ICI 118551, in one employing a low dose ( $0.1 \mathrm{mg} \mathrm{kg}^{-1}$ bolus; $0.05 \mathrm{mg} \mathrm{kg}^{-1} \mathrm{~h}^{-1}$ infusion) and in the other a higher dose $\left(1 \mathrm{mg} \mathrm{kg}^{-1}\right.$ bolus; $0.5 \mathrm{mg} \mathrm{kg}^{-1}$ $\mathrm{h}^{-1}$ infusion). In the former experiment 8 Long Evans and 8 Brattleboro rats were used, in the latter 7 Long Evans and 8 Brattleboro rats were studied. ICI 118551 was given throughout the experiment starting $60 \mathrm{~min}$ before the onset of administration of prazosin. Prazosin and idazoxan administration was then carried out as in Experiment 1.

\section{Experiment 3: Cardiovascular effects of prazosin and idazoxan administration in adrenal-demedullated animals}

Seven Long Evans rats were anaesthetized (2\% halothane in oxygen) and both adrenal medullae were removed by gentle extrusion through a slit made in the adrenal capsules. Animals were allowed at least 2 weeks to recover, during which time they showed no signs of adrenocortical insufficiency inasmuch as they thrived and gained weight without access to sodium supplementation (Gardiner et al., 1986). As above, animals were instrumented with intra-arterial and intravenous cannulae at least $5 \mathrm{~h}$ before experiments were begun. Following a $30 \mathrm{~min}$ baseline recording period, prazosin $\left(0.5 \mathrm{mg} \mathrm{kg}^{-1} ; 0.8 \mathrm{mg} \mathrm{kg}^{-1} \mathrm{~h}^{-1}\right)$ was administered. Twenty min later, while prazosin administration was continued, idazoxan 
$\left(0.75 \mathrm{mg} \mathrm{kg}^{-1} ; 1 \mathrm{mg} \mathrm{kg}^{-1} \mathrm{~h}^{-1}\right)$ was also given; both drugs were administered for a further $45 \mathrm{~min}$. The same protocol was run also in 8 control Long Evans rats. The results from the control animals were indistinguishable from those in Experiment 1 when the interval separating prazosin and idazoxan administrations was $45 \mathrm{~min}$.

\section{Experiment 4: The effects of captopril administration in the presence of prazosin and idazoxan}

In the presence of prazosin and idazoxan, captopril ( $2 \mathrm{mg} \mathrm{kg}^{-1}$ bolus; $1 \mathrm{mg} \mathrm{kg}^{-1} \mathrm{~h}^{-1}$ infusion) was administered to the Long Evans $(n=8)$ and Brattleboro $(n=7)$ rats in Experiment 1, at a time when a depressor episode was not occurring. Recordings were made for a further $30 \mathrm{~min}$, and the $\mathrm{V}_{1}$-receptor antagonist, $\mathrm{d}\left(\mathrm{CH}_{2}\right)_{5}$ DAVP was then administered $\left(10 \mu \mathrm{g} \mathrm{kg}^{-1}\right)$ to Long Evans rats. The dose of captopril used blocks the pressor actions of angiotensin I (125 ng) by about $90 \%$, and in the present experiments effectively abolished the pressor actions of the reninangiotensin system as judged by the sustained hypotension seen following its administration to Brattleboro rats receiving prazosin and idazoxan and in Long Evans rats following the additional administration of $\mathrm{d}\left(\mathrm{CH}_{2}\right)_{5} \mathrm{DAVP}$ (see Results).

\section{Experiment 5: Cardiovascular effects of repeated administration of phentolamine}

Seven Long Evans rats were given phentolamine $\left(1 \mathrm{mg} \mathrm{kg}^{-1} ; 1 \mathrm{mg} \mathrm{kg}^{-1} \mathrm{~h}^{-1}\right)$ and, $20 \mathrm{~min}$ later a second dose of the drug was administered $\left(1 \mathrm{mg} \mathrm{kg}^{-1}\right.$; $1 \mathrm{mg} \mathrm{kg}^{-1} \mathrm{~h}^{-1}$ ) through a separate venous catheter; both solutions were infused for the following $45 \mathrm{~min}$. At this juncture a bolus dose of ICI 118551 $\left(0.2 \mathrm{mg} \mathrm{kg}^{-1}\right)$ was injected and cardiovascular variables monitored for a further $20 \mathrm{~min}$.

\section{Experiment 6: Cardiovascular effects of central and peripheral administration of idazoxan in animals receiving phenoxybenzamine peripherally}

Five Long Evans rats had stainless steel (23 gauge) guide cannulae implanted in a lateral cerebral ventricle under sodium methohexitone anaesthesia $\left(60 \mathrm{mg} \mathrm{kg}^{-1}\right.$, i.p.) at least 7 days before the experiments. As above, these animals were instrumented with intra-arterial and intravenous catheters at least $5 \mathrm{~h}$ before measurements were made. Following at least $30 \mathrm{~min}$ baseline recording, phenoxybenzamine $\left(1 \mathrm{mg} \mathrm{kg}^{-1}\right.$; $0.5 \mathrm{mg} \mathrm{kg}^{-1} \mathrm{~h}^{-1}$ ) was administered intravenously, and was given throughout the rest of the experiment. Forty five min after the onset of phenoxybenzamine administration (when BP was steady), $2 \mu$ l of artificial cerebrospinal fluid (CSF) was administered into the lateral ventricle. At least $20 \mathrm{~min}$ later, when $\mathrm{BP}$ and HR were steady, $25 \mu \mathrm{g}$ of idazoxan (see Brown \& Harland, 1984) in $2 \mu \mathrm{l}$ artificial CSF was given into the lateral ventricle. This dose is sufficient to block central $\alpha_{2}$-adrenoceptors (Brown \& Harland, 1984) for at least $30 \mathrm{~min}$ (D.B. Harland, personal communication, 1987). Central injections were given through a microinjector previously connected to the guide cannula so animals were undisturbed during administrations. Twenty min after central administration of idazoxan (i.e. at a time when central $\alpha_{2}$-adrenoceptors would still have been blocked), animals received idazoxan intravenously $\left(0.75 \mathrm{mg} \mathrm{kg}^{-} ; 1 \mathrm{mg} \mathrm{kg}^{-1} \mathrm{~h}^{-1}\right)$.

\section{Drugs}

The following drugs were used:- phentolamine mesylate (Ciba); phenoxybenzamine hydrochloride (SK \& F); idazoxan hydrochloride (Reckitt \& Colman); prazosin hydrochloride (Pfizer); ICI 118551 (erythro-( \pm )-1-[7-methylindan-4-yloxy]-3-isopropylaminobutan-2-ol, ICI Pharmaceuticals plc); captopril (Squibb); d( $\left.\mathrm{CH}_{2}\right)_{5}$ DAVP (1-[ $\beta$-mercapto- $\beta, \beta$-cyclopentamethylknepropionic acid]-8-D-arginine vasopressin) (Professor Manning).

Bolus injections were given in a volume of $100 \mu \mathrm{l}$ and the subsequent infusion rate was $300 \mu \mathrm{h} \mathrm{h}^{-1}$. Prazosin was dissolved in a small volume of lactic acid $(0.04 \mathrm{M}$ in dextrose), and diluted in $5 \%$ dextrose. All other drugs given intravenously were dissolved in isotonic saline (gentle heating was required for ICI 118551).

\section{Statistical analyses}

Values are expressed as a mean \pm s.e.mean; $n$ is the number of animals. Differences were analysed for statistical significance using the Peritz $F$ test for multiple comparisons (Harper, 1984). Paired differences were analysed using Student's paired $t$ test; significance was accepted when $P<0.05$.

\section{Results}

In the resting state there were no significant differences between the BPs or HRs of Long Evans and Brattleboro rats.

\section{Experiment 1: The effects of sequential administration of prazosin and idazoxan (Figure 2 and 3 )}

The initial hypotensive responses to prazosin were similar in Long Evans and Brattleboro rats $(-62 \pm 5 /$ $-35 \pm 3 ;-44 \pm 5 /-29 \pm 5 \mathrm{mmHg}$ systolic/diastolic BP, respectively) as were the tachycardias. Within 10 min, diastolic BP had recovered to baseline levels, but over the following $45 \mathrm{~min}$ systolic BP never recovered fully, and there was a sustained tachycardia in both strains. (The HR change is not likely to have 
been responsible for the systolic hypotension (see methods), but the latter could have been due to a fall in cardiac output consequent upon an increase in venous capacitance. The recovery in diastolic BP under these conditions could have been due to a recovery in arteriolar resistance).

Idazoxan, given in the presence of prazosin initially caused similar falls in BP in Long Evans and Brattleboro rats $(-51 \pm 5 / 39 \pm 2 ;-55 \pm 4 / 37 \pm 2 \mathrm{mmHg}$, respectively) and associated tachycardias. There then followed a prompt recovery in BP with the peak level being attained 3-4 min after idazoxan had been given. The BP reached at this stage (Long Evans 147 \pm 8 / $93 \pm 6 \mathrm{mmHg}$, Brattleboro $161 \pm 6 / 102 \pm 3 \mathrm{mmHg}$ ) was always higher than the level recorded immediately before idazoxan was given, but was not different from control levels; in spite of this there was bradycardia (Long Evans $-94 \pm 8$, Brattleboro $-61 \pm 9$ beat $\min ^{-1}$ ).

During the time when prazosin and idazoxan were being administered together, the BPs and HRs showed marked oscillations in both strains of rat. Since the frequencies and durations of the oscillations in BP and HR were not constant either within, or between, animals it was not possible to reduce the results to group mean data. Hence, representative traces are also shown to illustrate the findings (Figure $1 \mathrm{~b}$ and 2). There were no obvious differences between the results for Long Evans and Brattleboro rats. However, BP values recorded about $45 \mathrm{~min}$ after the start of idazoxan administration (measured at a time when a depressor episode was not occurring) were slightly lower than the original control values in the Long Evans rats $(P<0.05$ for systolic only) but were not different from the control values in the Brattleboro rats (Figure 3).

Careful examination of traces run out at high speed showed a very close association between BP and HR changes. But it was also clear that the magnitude of hypotensive events was not directly related to the size of the tachycardias. Furthermore, in other experiments (see below) substantial tachycardias or bradycardias occurred in the absence of marked changes in BP.

\section{Experiment 2: The effects of sequential administration} of prazosin and idazoxan in the presence of ICI 11855I (Figure 4 and 5)

The low dose of ICI 118551 had no significant effects
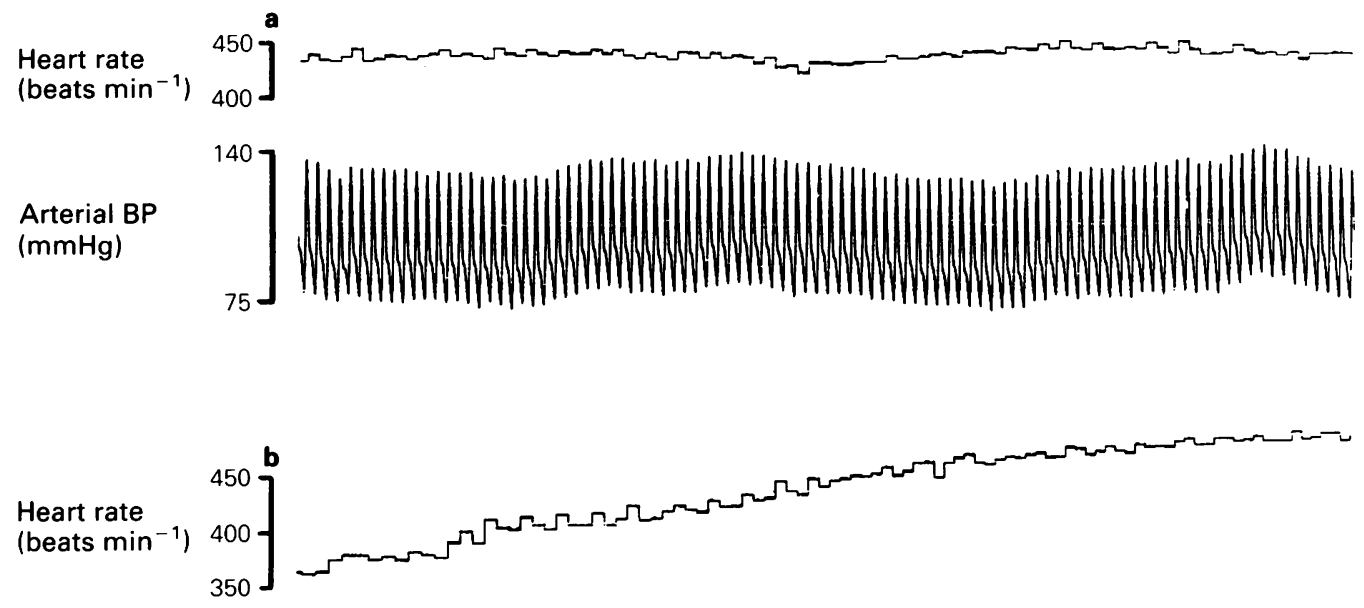

Arterial BP $(\mathrm{mmHg})$

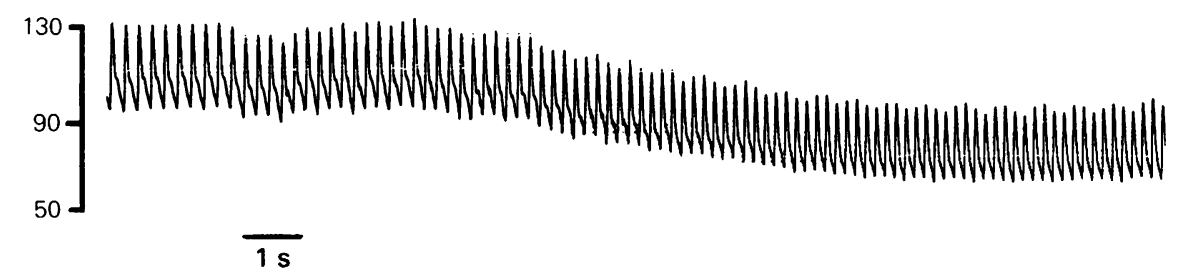

Figure 1 Recording of the intra-arterial blood pressure profile and associated pulse interval (electronically converted to instantaneous heart rate) in a Long Evans rat: (a) baseline recording; (b) in the presence of prazosin and idazoxan at the onset of a depressor episode (see text). 


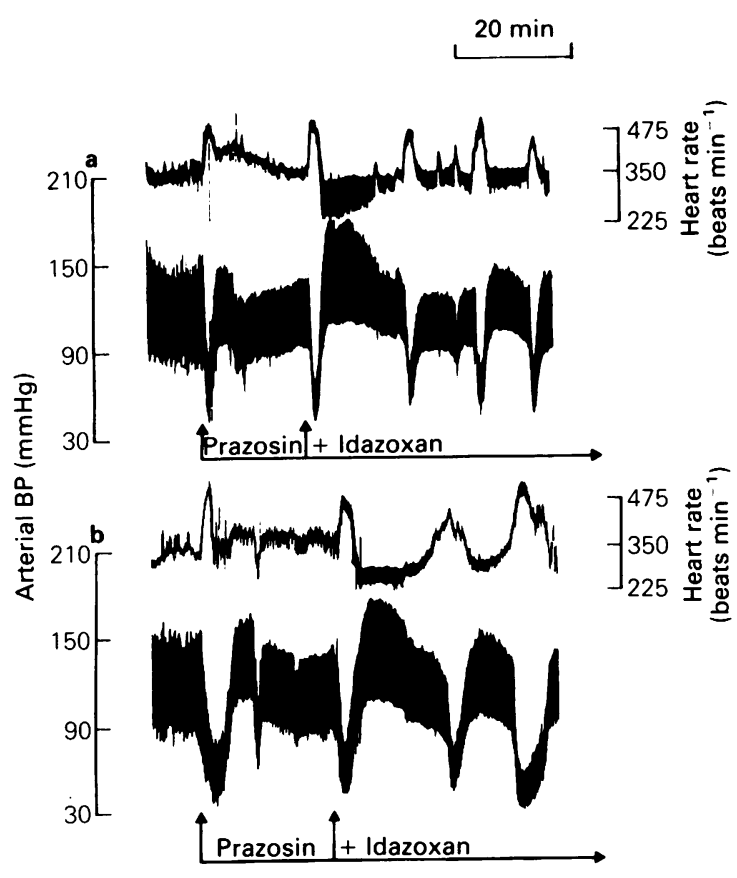

Figure 2 Recordings of intra-arterial blood pressures and heart rate in a representative Long Evans (a) and Brattleboro (b) rat. In both strains, in the presence of prazosin ( $0.5 \mathrm{mg} \mathrm{kg}^{-1}$ bolus, $0.8 \mathrm{mg} \mathrm{kg}^{-1} \mathrm{~h}^{-1}$ infusion) and idazoxan $\left(0.75 \mathrm{mg} \mathrm{kg}^{-1}\right.$ bolus, $1 \mathrm{mg} \mathrm{kg}^{-1} \mathrm{~h}^{-1}$ infusion), there were marked depressor episodes accompanied by tachycardias. These variabilities in blood pressures and heart rates are represented by the dotted lines in Figure 3.

on BP or HR (Figure 4). Administration of prazosin subsequently caused similar falls in BP and increases in HR in Long Evans and Brattleboro rats $(-19 \pm 3 /$ $14 \pm 2 \mathrm{mmHg},+76 \pm 13$ beats $\min ^{-1} ;-18 \pm 2 /$ $15 \pm 2 \mathrm{mmHg},+81 \pm 12$ beats $\min ^{-1}$, respectively). The changes in BP and HR were significantly $(P<0.05)$ less than those seen following prazosin alone (Experiment 1), but the hypotensions were more affected than the tachycardias. Within $10 \mathrm{~min}$ after prazosin administration there was no difference between the results from the two experiments.

Administration of idazoxan in the presence of ICI 118551 and prazosin caused transient, slight hypotensions and tachycardias, followed by pronounced bradycardias in both Long Evans and Brattleboro rats (Figures, 4 and 5). The depressor changes and bradycardias were significantly $(P<0.05)$ less than those seen in Experiment 1, although the nadirs in heart rate were similar in the two experiments (in spite of a total absence of a post-idazoxan overshoot in BP in the presence of ICI 118551).

In the presence of ICI 118551, prazosin and idazoxan there were only slight, intermittent depressor episodes, although there were substantial bouts of tachycardia, particularly in the Brattleboro rats (Figure 5). These dissociations between changes in HR and BP argue against the possibility that the latter were caused by the former.

The high dose of ICI 118551 had a transient pressor effect accompanied by a persistent bradycardia in both strains of rat (Figure 4). Prazosin, in the presence of the high dose of ICI 118551, caused similar, significant falls in BP in Long Evans rats and Brattleboro rats $(-14 \pm 3 / 10 \pm 2 ;-16 \pm 4 / 13 \pm 4 \mathrm{mmHg}$, respectively). These effects were less $(P<0.05)$ than occurred when prazosin was given alone (Experiment 1) but not different from those observed in the presence of the lower dose of ICI 118551 (see above).

Idazoxan given in the presence of the high dose of ICI 118551 and prazosin caused no significant change in BP in the Long Evans rats but a significant, although small, and transient, fall in BP $(-14 \pm 4$ / $10 \pm 2 \mathrm{mmHg}$ ) in the Brattleboro rats (Figures 4 and 5). During the combined administration of the high dose of ICI 118551, prazosin and idazoxan there were occasional, slight changes in BPs (particularly in the Brattleboro rats) associated with substantial tachycardias (Figure 5); such events tended to be smaller in magnitude in Long Evans rats (Figure 5).

\section{Experiment 3: Cardiovascular effects of prazosin and idazoxan administration in adrenal-demedullated rats (Figures 6 and 7)}

In the resting state BPs in adrenal demedullated, Long Evans rats were $146 \pm 4 / 93 \pm 3 \mathrm{mmHg}$ and $\mathrm{HR}$ was $386 \pm 12$ beats $\min ^{-1}(P<0.05$ for HR against control). Prazosin caused a transient fall in BP (nadir $-37 \pm 3 / 25 \pm 2 \mathrm{mmHg})$ and tachycardia $(+81 \pm 17$ beats $\mathrm{min}^{-1}$ ), but systolic BP had plateaued below $(P<0.05)$ the resting level $(132 \pm 4 / 91 \pm 3 \mathrm{mmHg})$ and $H R$ remained elevated $\left(415 \pm 13\right.$ beats min $\left.^{-1}\right)$ $20 \mathrm{~min}$ after the onset of prazosin administration. Additional administration of idazoxan caused a transient hypotension $(-27 \pm 3 / 20 \pm 2 \mathrm{mmHg}$ ), but within 3-4 min there was an overshoot in BP (154 $\pm 7 /$ $101 \pm 5 \mathrm{mmHg})$ and a bradycardia $(290 \pm 17$ beats $\min ^{-1}$ ) relative to the pre-idazoxan condition. Thereafter BP and HR (generally) returned to the preidazoxan levels, and BP was relatively stable in spite of intermittent bouts of substantial tachycardia (Figure 7).

The hypotensive effects of prazosin and idazoxan in adrenal demedullated Long Evans rats were significantly $(P<0.05)$ less than those in control 
b
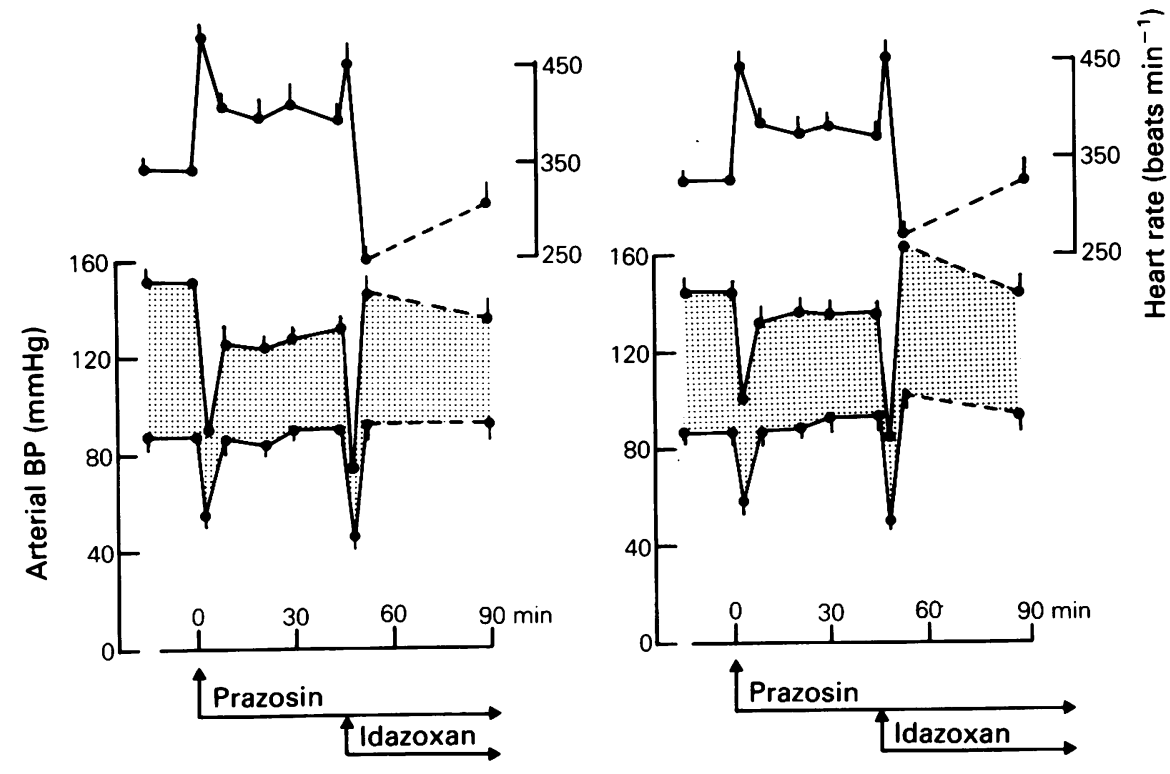

Figure 3 Changes in blood pressures and heart rates (mean with s.e.mean shown by vertical lines) in response to the sequential administration of prazosin and idazoxan in Long Evans $(a ; n=8)$ and Brattleboro $(b ; n=7)$ rats. Drug doses as in Figure 2. The dotted lines indicate the occurrence of marked variability in cardiovascular status, as shown in Figure 2. The values shown $\mathbf{4 5}$ min after administration of idazoxan represent those seen when a depressor episode was not occurring.

animals, but significantly $(P<0.05)$ greater than those in the presence of ICI 118551 (Experiment 2).

\section{Experiment 4: The effects of captopril administration in the presence of prazosin and idazoxan}

Forty five min after administration of idazoxan in the presence of prazosin, and when a depressor episode was not occurring, injection of captopril caused substantial hypotensions in both strains of rat (Long Evans - 69 $\pm 6 / 48 \pm 6 \mathrm{mmHg}$; Brattleboro - $76 \pm 6$ / $55 \pm 3 \mathrm{mmHg}$ ).

In Brattleboro rats the low BP was sustained under these conditions $(65 \pm 4 / 35 \pm 3 \mathrm{mmHg}$ at $30 \mathrm{~min})$ and HR was steady $\left(374 \pm 22\right.$ beats $\left.\mathrm{min}^{-1}\right)$. In Long Evans rats, BP recovered from the nadir (peak increase: $+23 \pm 5 / 16 \pm 4 \mathrm{mmHg}$ ), but continued to fluctuate, as did HR. Additional administration of $\mathrm{d}\left(\mathrm{CH}_{2}\right)_{5}$ DAVP caused a sustained hypotension and steady $H R$ in Long Evans rats $(64 \pm 3 / 32 \pm$ $2 \mathrm{mmHg} ; 350 \pm 21$ beats $\mathrm{min}^{-1}$ at $15 \mathrm{~min}$ ).

\section{Experiment 5: Cardiovascular effects of repeated administration of phentolamine (Figure 8)}

Admimistration of the first dose of phentolamine caused marked, but transient hypotension $(-63 \pm 3$ / $39 \pm 2 \mathrm{mmHg}$ ) but subsequently BP was relatively steady. On administration of the second dose of phentolamine BP fell $(-50 \pm 3 / 33 \pm 3 \mathrm{mmHg})$ and recovered again, but afterwards $B P$, and, to a lesser extent, HR, showed marked instability. If ICI 118551 was administered when a depressor episode was occurring, BP rose dramatically and remained steady thereafter (Figure 8). If ICI 118551 was given when BP was not low, it had little immediate pressor effect, but subsequently depressor episodes were abolished.

\section{Experiment 6: Cardiovascular effects of central and peripheral administration of idazoxan in animals receiving phenoxybenzamine peripherally (Figure 9)}

Phenoxybenzamine had modest effects on BP and they 


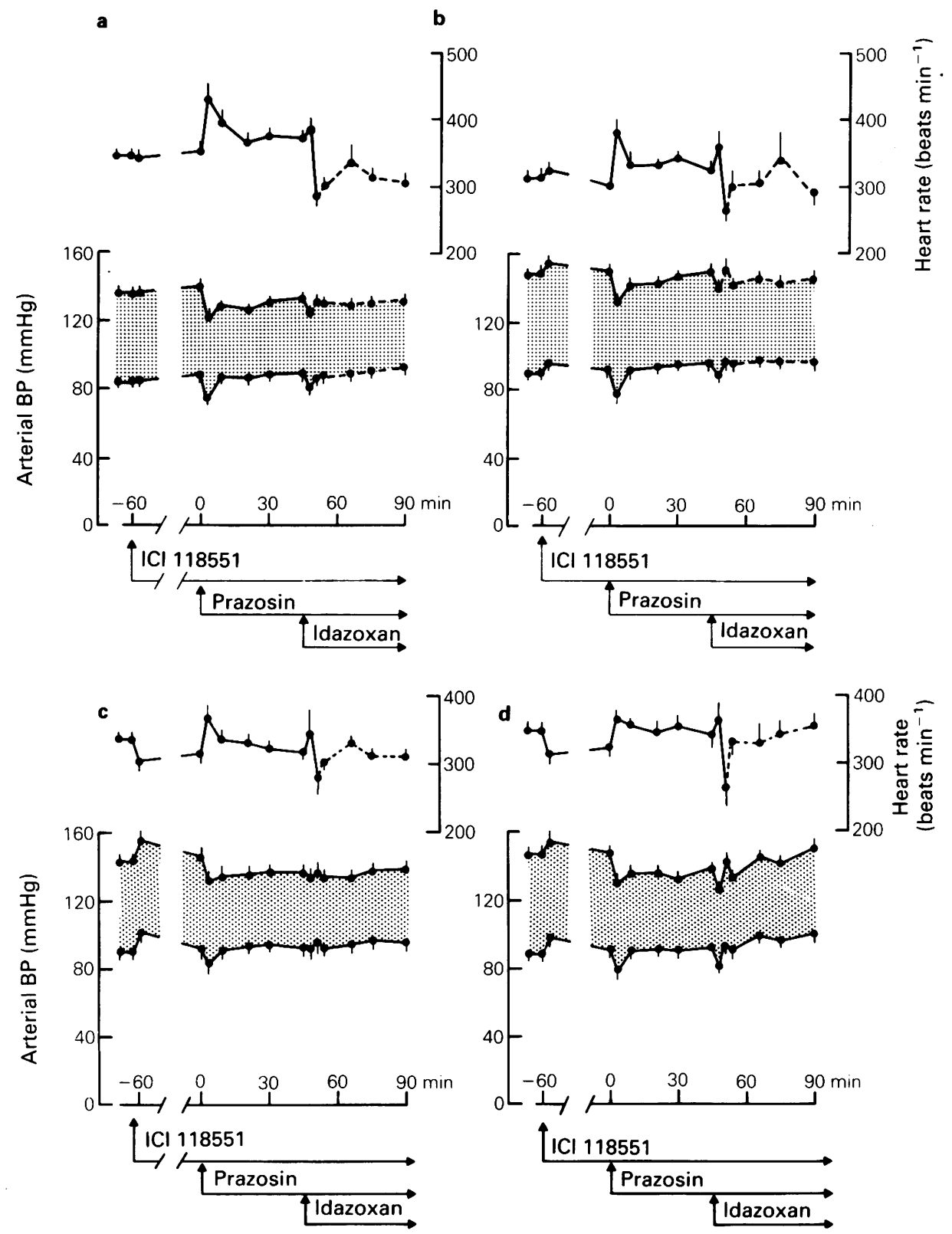

Figure 4 Changes in blood pressures and heart rates (mean with s.e.mean shown by vertical lines) in response to the sequential administration of prazosin and idazoxan in the presence of a low dose (a,b) of ICI $118551\left(0.1 \mathrm{mg} \mathrm{kg}^{-1} \mathrm{bolus}\right.$, $0.05 \mathrm{mg} \mathrm{kg}^{-1} \mathrm{~h}^{-1}$ infusion) and in the presence of a high dose (c,d) of ICI $118551\left(1 \mathrm{mg} \mathrm{kg}^{-1} \mathrm{bolus} 0.5 \mathrm{mg} \mathrm{kg}^{-1} \mathrm{~h}^{-1}\right.$ infusion) in Long Evans rats $(a, c)$ or Brattleboro rats $(b, d)$. The dotted lines indicate variability in blood pressures and/ or heart rates (see Figure 5). Prazosin and idazoxan doses as in Figure 2. 

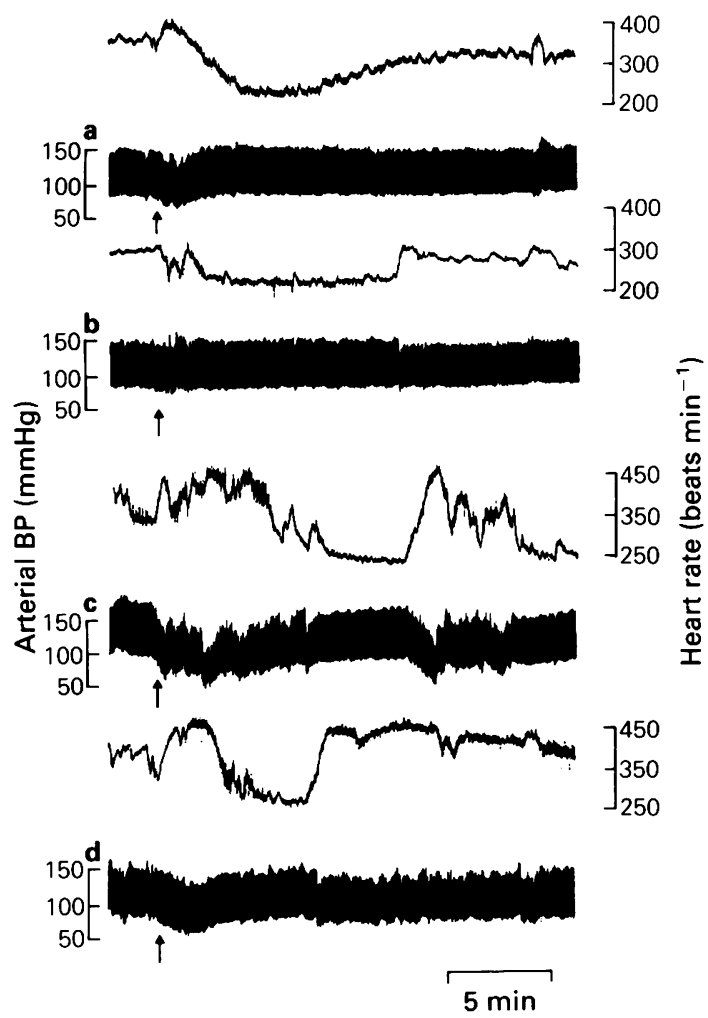

Figure 5 Representative tracings from individual Long Evans and Brattleboro rats showing the responses to idazoxan administration (at arrow) in the presence of low dose ICI 118551 and prazosin (Long Evans, a; Brattleboro, c) or high dose ICI 118551 and prazosin (Long Evans, b; Brattleboro, d). In the presence of the high dose of ICI 118551 and prazosin, idazoxan had no hypotensive effect in the Long Evans rat, although heart rate changes still occurred. There was a slight hypotensive response to idazoxan and the Brattleboro rat and heart rate changes were prominent. Drug doses as in Figure 2 and 4.

developed slowly over the $45 \mathrm{~min}$ when this drug was administered alone (Figure 9). Intracerebroventricular administration of artificial CSF had no significant effects on cardiovascular variables. However, intracerebroventricular administration of idazoxan caused a small but significant $(P<0.05)$ fall in BP and a tachycardia (Figure 9); these effects were transient and subsequently BP was well-maintained. But, in all animals, when idazoxan was given intravenously BP showed a marked fall (Figure 9), and thereafter there were intermittent depressor episodes indistinguishable from those seen in the presence of prazosin and idazoxan.

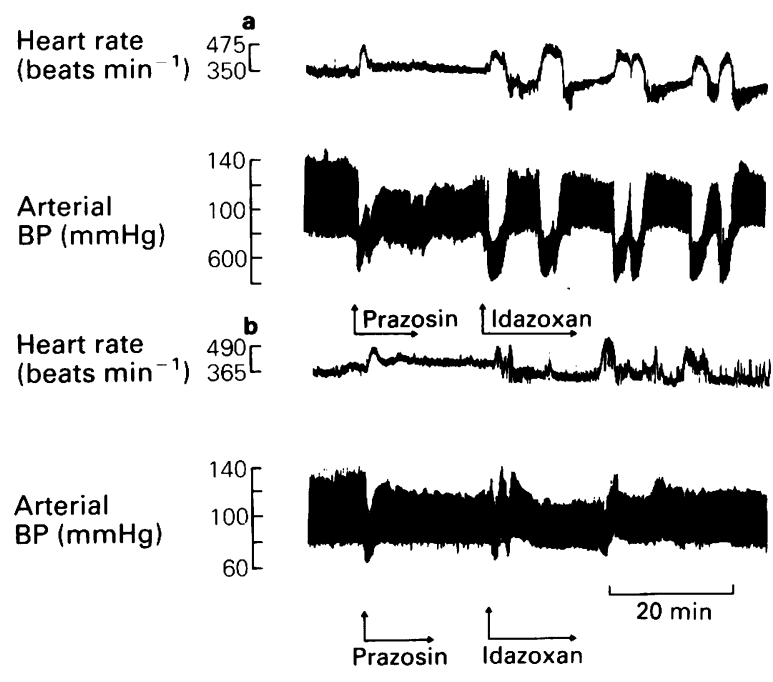

Figure 6 Cardiovascular responses to administration of prazosin $20 \mathrm{~min}$ before idazoxan in a conscious, unrestrained control (a) and adrenal demedullated (b) Long Evans rat. In the latter, hypotensive responses to drug administrations were attenuated and in the presence of both drugs BP was relatively stable, although intermittent tachycardias occurred. Drug doses as in Figure 2.

\section{Discussion}

For reasons given in the methods and results, it seems likely that the phenomena described in this paper were not methodological artefacts, and that the druginduced changes in BP were not largely secondary to chronotropic events influencing cardiac output. Indeed, we have found recently (Bennett et al., 1986a; $1987 \mathrm{a}, \mathrm{b})$ by direct measurement, that drug-induced hypotensions were associated with active vasodilatations, particularly in the hindquarters. This, of course, does not exclude the possibility of a change in cardiac output occurring in our experimental protocols; as pointed out above, such a change could have been responsible for the persistent systolic hypotension in the presence of prazosin.

The main aim of the present study was to explore the possible involvement of $\boldsymbol{\beta}_{2}$-adrenoceptor-mediated effects in the hypotensive responses to $\alpha$-adrenoceptor antagonism in conscious, unrestrained rats. The results show that the initial hypotensive responses to $\alpha_{1}$-adrenoceptor antagonism (with prazosin) were markedly inhibited by pretreatment with a $\beta_{2}$-adrenoceptor antagonist (ICI 118551), suggesting that $\boldsymbol{\beta}_{2}$ adrenoceptor-mediated events were probably con- 

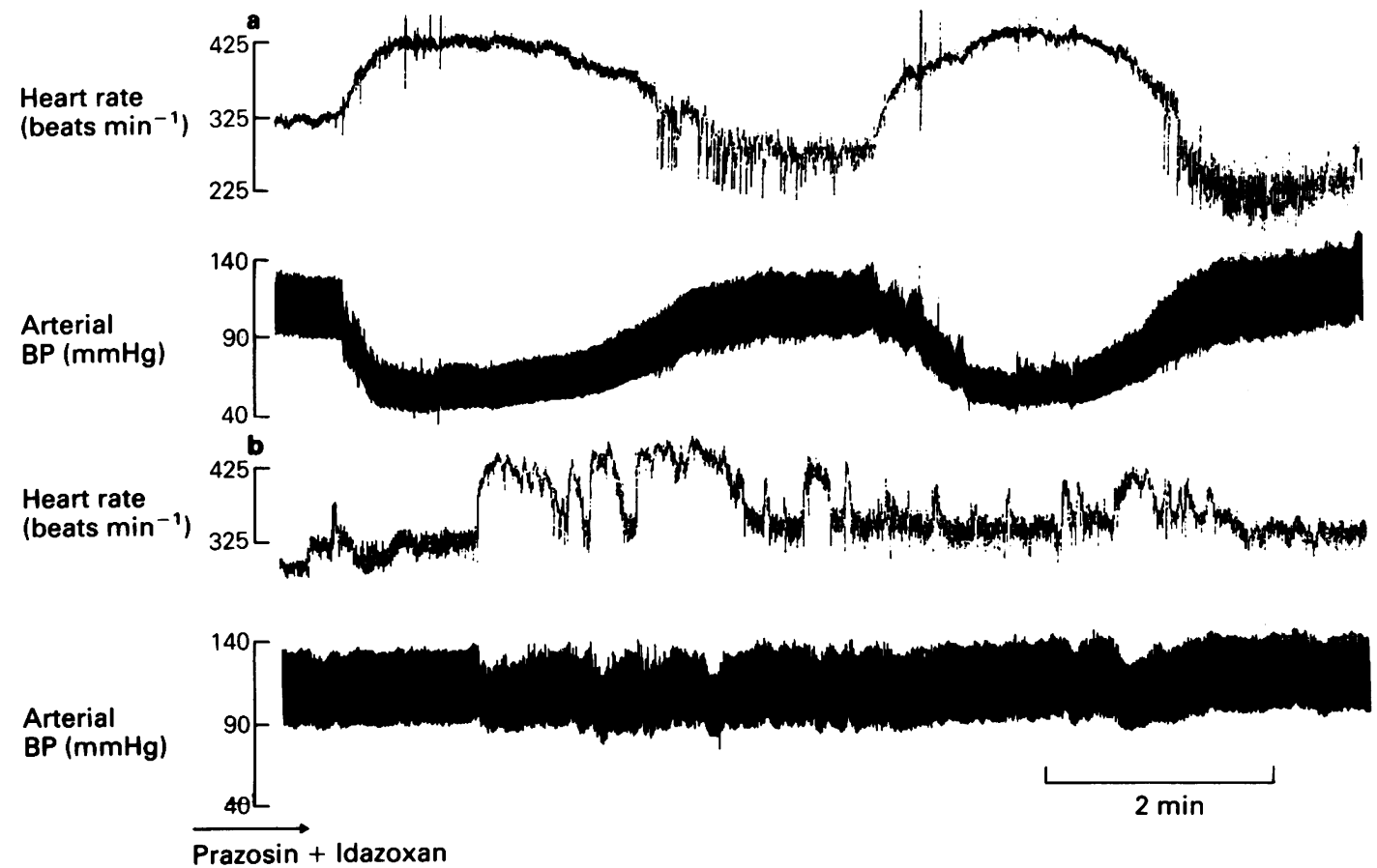

Figure 7 Blood pressures and heart rates in a control (a) and an adrenal-demedullated, Long Evans rat (b) in the presence of prazosin and idazoxan. The depressor episodes in the control rat are barely apparent in the adrenaldemedullated rat, although the amplitudes of heart rate increases are similar in both. Drug doses as in Figure 2.

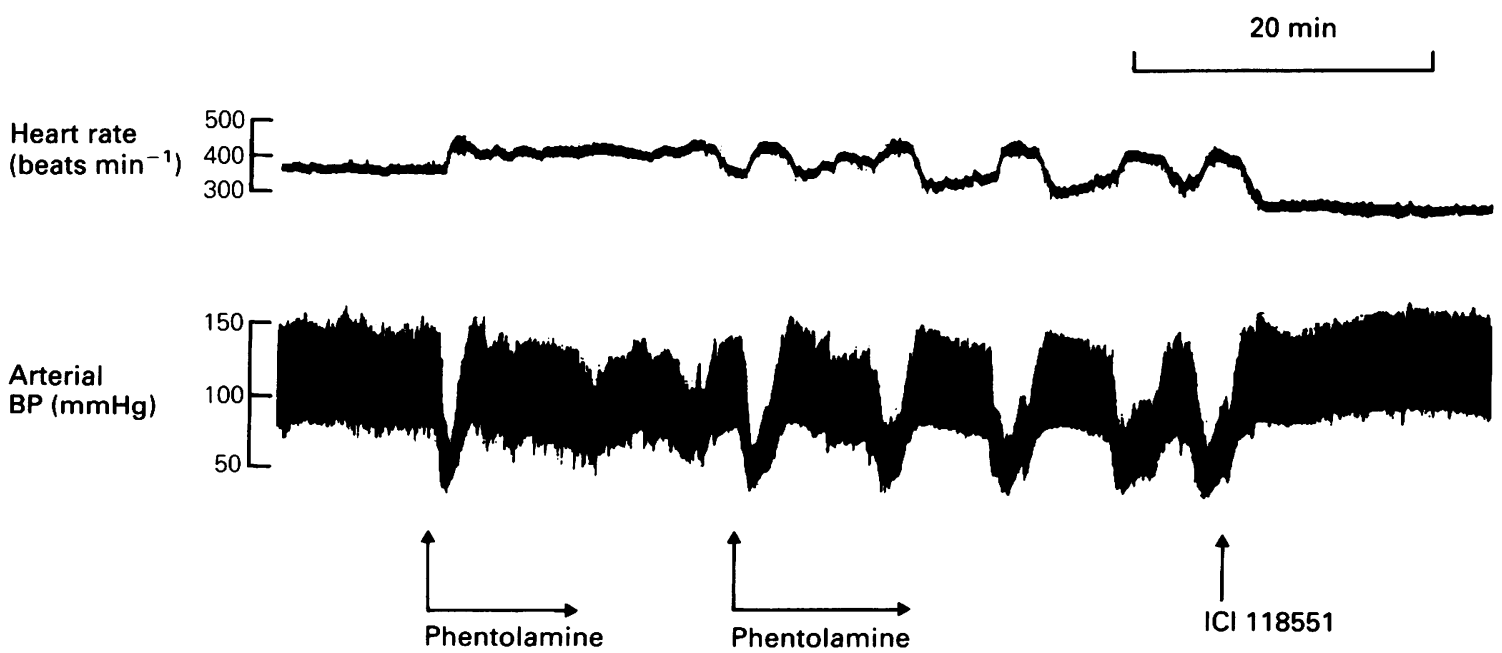

Figure 8 Conscious, unrestrained, Long Evans rat receiving two primed infusions of phentolamine $\left(1 \mathrm{mg} \mathrm{kg}^{-1}\right.$, $\left.1 \mathrm{mg} \mathrm{kg}^{-1} \mathrm{~h}^{-1}\right), 20 \mathrm{~min}$ apart. Although the first dose of drug caused a transient hypotension, blood pressures were then relatively stable until the second dose was administered. During a depressor episode, administration of ICI 118551 $\left(0.2 \mathrm{mg} \mathrm{kg}^{-1}\right.$ bolus) was associated with a marked increase in blood pressure and subsequently depressor episodes did not occur. 


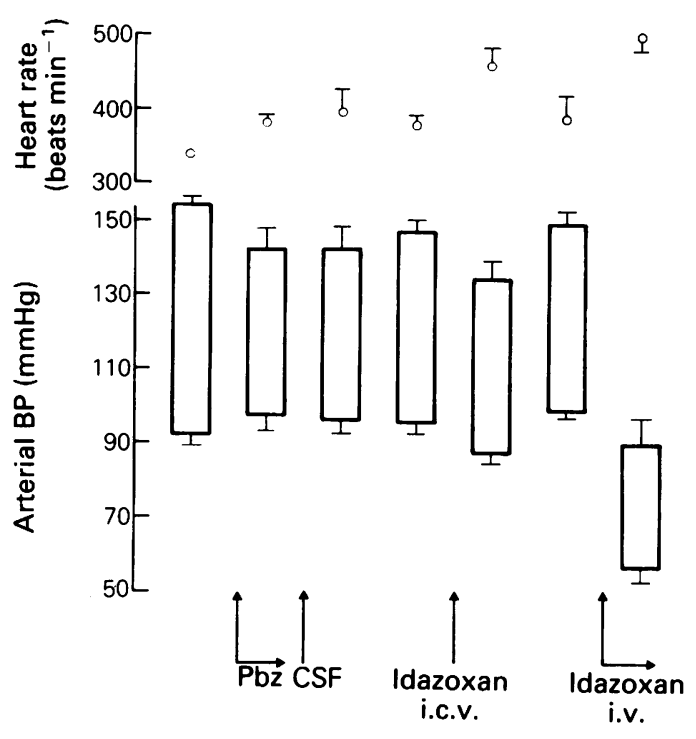

Figure 9 Group mean $(n=5)$ responses in conscious, unrestrained, Long Evans rats with lateral ventricular cannulae. Forty five min after the onset of phenoxybenzamine ( $\mathrm{Pbz}, 1 \mathrm{mg} \mathrm{kg}^{-1}, 0.5 \mathrm{mg} \mathrm{kg}^{-1} \mathrm{~h}^{-1}$ ) administration systolic blood pressure and heart rate were significantly $(P<0.05)$ different from resting levels. Intracerebroventricular (i.c.v.) administration of $2 \mu$ l artificial cerebrospinal fluid (CSF) had no significant effects on blood pressures or heart rate, but $25 \mu \mathrm{g}$ idazoxan in $2 \mu \mathrm{l} \mathrm{CSF}$ given i.c.v. (Idazoxan, i.c.v) caused tachycardia, associated with reductions in systolic and diastolic blood pressures in all animals. These effects were transient (see methods) and subsequently intravenous administration of idazoxan (Idazoxan i.v., $0.75 \mathrm{mg} \mathrm{kg}^{-1}, 1 \mathrm{mg} \mathrm{kg}^{-1} \mathrm{~h}^{-1}$ ) caused marked hypotension with a time course similar to that seen in the presence of prazosin (see Figure 2 and 6 ).

tributing importantly to the haemodynamic effects of prazosin. The fact that ICI 118551 exerted these effects at a dose that had none of the actions associated with $\beta_{1}$-adrenoceptor antagonism argues in favour of the selective $\boldsymbol{\beta}_{2}$-adrenoceptor nature of this influence. In adrenal-demedullated, Long Evans rats the depressor effect of prazosin was attenuated, but less so than by $\beta_{2}$-adrenoceptor antagonism with ICI 118551 . Collectively these results indicate that both the adrenal medulla and (reflex) neuronal catecholamine release may have contributed to the $\boldsymbol{\beta}_{2}$-adrenoceptormediated component of the hypotensive response to prazosin.

There were no differences between the Long Evans and Brattleboro rats in their initial hypotensive responses to prazosin, and subsequently BP recovered similarly in both strains under all conditions. Thus, like Waeber et al. (1983) we found no evidence for an essential role of vasopressin in maintaining BP following $\alpha_{1}$-adrenoceptor antagonism with prazosin.

In the presence of prazosin there was a marked, but transient, hypotensive response to $\alpha_{2}$-adrenoceptor antagonism with idazoxan (an effect not seen when idazoxan is given alone (Bennett et al., 1984)). This hypotension could have been due to several things, including antagonism of $\alpha_{2}$-adrenoceptor mediated vasoconstrictor tone (McGrath, 1982), which had been recruited following administration of prazosin (Sawyer et al., 1985; Warnock \& Docherty, 1986), and/or to activation of a $\boldsymbol{\beta}_{2}$-adrenoceptor-mediated depressor mechanism, due to the increased circulating catecholamine levels caused by idazoxan (Brown \& Harland, 1984; 1986), possibly as a result of antagonism of prejunctional, autoinhibitory, $\alpha_{2}$-adrenoceptors. Others have shown (in anaesthetized rats) that $\alpha_{2}$ adrenoceptor antagonism with rauwolscine (in the presence of prazosin) caused a fall in BP which was prevented by adrenal demedullation (Sawyer et al., 1985; Warnock \& Docherty, 1986). From those observations it was concluded that following administration of prazosin, ' $\alpha_{2}$-vascular adrenoceptors' were responsible for maintaining $\mathrm{BP}$ and that the adrenal medulla was the major source of catecholamines for this effect. But our present finding that ICI 118551 could completely prevent the hypotensive effects of idazoxan in Long Evans rats suggests that a major component of the hypotensive response to $\alpha_{2}$-adrenoceptor antagonism in these animals was due to $\beta_{2}-$ adrenoceptor mediated events. However, the lack of any change in BP following administration of idazoxan in the presence of ICI 118551 and prazosin cannot be taken to indicate the absence of postjunctional $\alpha_{2}$-adrenoceptors, since any effects of antagonizing the latter may have been offset by recruitment of other mechanisms. In Brattleboro rats the hypotensive effect of idazoxan was not abolished by the high dose of ICI 118551. Thus in these animals postjunctional $\alpha_{2}$-adrenoceptors may contribute to BP maintenance in a way not apparent in Long Evans rats.

The results in the adrenal-demedullated rats in the present study indicate that it is likely that the adrenal medullae contributed significantly to the $\boldsymbol{\beta}_{2}$-adrenoceptor-mediated responses following administration of idazoxan to intact rats, but probably not more so than neuronal catecholamine release. Although there are reports from in vitro studies which suggest that adrenal medullary adrenaline release is not influenced by $\alpha_{2}$-adrenoceptors (Sharma et al., 1986), studies in conscious rats have shown increases in circulating adrenaline levels following peripheral administration of idazoxan (Brown \& Harland, 1986). Thus it may be that elevated catecholamine levels result from effects of idazoxan on chromaffin cells (Bouvier \& de Champ- 
lain, 1983) as well as reflex activation of sympathetic efferent outflow and antagonism of prejunctional autoinhibitory feedback.

In the presence of prazosin and idazoxan, when a depressor episode was not occurring, BPs were little different from the pre-drug levels. It is likely that this was due to activation of the renin-angiotensin system, since administration of captopril caused substantial falls in BP in Long Evans and Brattleboro rats, and this effect was sustained in the latter animals. The recovery in BP seen in Long Evans rats in the presence of prazosin, idazoxan and captopril was abolished by the $V_{1}$-receptor antagonist. These observations are consistent with a pressor action of endogenous vasopressin under these conditions, but provide no information about the possible involvement of vasopressin in Long Evans rats in the presence of prazosin and idazoxan prior to the administration of captopril. However, during concurrent administration of prazosin and idazoxan there were no obvious differences between Long Evans and Brattleboro rats. Thus, neither disinhibition of vasopressin release by $\alpha_{2}$-adrenoceptor antagonism (Brooks et al., 1986) nor an inhibitory effect of vasopressin on renin release (Knepel et al., 1982) was reflected overtly in the BP profiles.

Activation of the renin-angiotensin system following $\alpha$-adrenoceptor antagonism has been reported in other studies (see Introduction) in which the changes in BP were quite different from those found in the present work. It is feasible that in the presence of prazosin and idazoxan, the intermittent depressor episodes (through reflex and direct effects on renin release) amplified the activation of the renin-angiotensin system. Furthermore, if the depressor episodes are dependent upon intermittent adrenal medullary activity (see below), circulating catecholamines could also contribute to stimulation of the renin-angiotensin system (particularly since $\alpha_{2}$-adrenoceptors inhibiting renin release (Summers, 1984) would be antagonized in the presence of idazoxan).

The intermittent depressor episodes seen in the presence of prazosin and idazoxan were virtually abolished by ICI 118551 or by adrenal demedullation. These results point to periodic release of adrenal medullary catecholamines being largely responsible for $\boldsymbol{\beta}_{2}$-adrenoceptor-mediated depressor events. The occurrence of tachycardias unaccompanied by BP changes in animals treated with ICI 118551 could have been due to circulating catecholamines, released from the adrenal medulla, stimulating cardiac $\boldsymbol{\beta}_{1}$-adrenoceptors. However, the finding that adrenaldemedullated animals also showed intermittent tachycardias (accompanied by only small BP changes) is consistent with a component of the HR response being due to episodic cardiac neuronal activation, and argues against the changes in BP being secondary to changes in HR in the intact animals.

We found intermittent depressor episodes (similar to those seen in the presence of prazosin and idazoxan) occurred when a sufficient dose of phentolamine was given, or when a combination of phenoxybenzamine and idazoxan was administered intravenously. Since phentolamine is a non-selective $\alpha$-adrenoceptor antagonist, one possible explanation of why BP instability was not seen with the doses of this drug used previously (Winn et al., 1985) is that the effects of phentolamine on $\alpha_{2}$-adrenoceptors is less marked than those of idazoxan. However, the dose of phentolamine used previously causes adequate blockade of postjunctional $\alpha_{2}$-adrenoceptors (Winn, 1985), so these findings may indicate that prejunctional $\alpha_{2}$-adrenoceptors need to be blocked (in the presence of $\alpha_{1}$-adrenoceptor antagonism) in order for BP instability to be induced. This proposition is consistent with the finding that idazoxan is more potent than phentolamine at prejunctional $\alpha_{2}$-adrenoceptors (Levitt \& Hieble, 1986). Since we do not know if higher doses of phenoxybenzamine alone would have induced BP instability, we cannot dismiss the possibility that a central action of phentolamine contributed to its effects (but see below).

The finding that ICI 118551 abolished BP instability induced by phentolamine indicates that this phenomenon was similar to that seen with a combination of prazosin and idazoxan. Furthermore, the observation that administration of ICI 118551 only had a pressor effect when BP was low corroborates our suggestion that the variation in BP was due to intermittent, $\boldsymbol{\beta}_{2}$ adrenoceptor-mediated, depressor events superimposed on a well-maintained BP. It is not clear why Gomes et al. (1978) did not observe BP instability in the presence of high doses of phentolamine, especially since they produced evidence that $\boldsymbol{\beta}_{2}$-adrenoceptor mechanisms contributed to the hypotensive effects of phentolamine. However, in their studies BP showed no recovery in the presence of phentolamine; a similar lack of BP recovery following phentolamine administration was also observed by Burnier et al. (1983).

It seems unlikely the BP instability we observed was due to antagonism of central $\alpha_{2}$-adrenoceptors alone since, in the presence of phenoxybenzamine, intracerebroventricular administration of idazoxan in a dose sufficient to block central $\alpha_{2}$-adrenoceptors did not prompt the occurrence of depressor episodes. Furthermore, in the presence of central $\alpha_{2}$-blockade, intravenous injection of idazoxan (when phenoxybenzamine was being given peripherally) did cause BP instability. However, there is a theoretical possibility that idazoxan given intravenously acts at a central site that is inaccessible to the drug when it is given into a lateral ventricle. In addition, since idazoxan administered peripherally gains access to the brain, we cannot categorically exclude the possibility that, in the presence of peripheral $\alpha_{1}$-adrenoceptor antagonism, 
depressor episodes induced by intravenous administration of idazoxan are dependent upon concurrent antagonism of peripheral and central $\alpha_{2}$-adrenoceptors. While a selective $\alpha_{2}$-adrenoceptor antagonist incapable of crossing the blood brain barrier might be helpful in this respect, that would only be the case if the central $\alpha_{2}$-adrenoceptors of interest were beyond the blood brain barrier. Since phentolamine given intravenously gains access to the brain, the fact that a high dose of this drug also induced BP instability does not help in resolving this point.

In passing, it is noteworthy that central administration of idazoxan alone has no effects on BP (Harland, 1985). Hence the transient depressor effects of this manoeuvre in the present study (when phenoxybenzamine was being given intravenously) may have been due to the unmasking of $\beta$-adrenoceptor effects due to catecholamine release in the periphery (Brown \& Harland, 1984; Harland, 1985).

One possible explanation of the intermittent depressor episodes seen in the presence of prazosin and idazoxan is that the loss of autoinhibitory control of neuronal and adrenal medullary catecholamine release, and the unmasking of pre- and postjunctional $\boldsymbol{\beta}_{2}$-adrenoceptor-mediated effects amplifies the hypotensive influences of intermittent sympathoadrenal activation originating from episodic (descending) excitation of preganglionic neurones. This proposition is consistent with our recent finding (S.M. Gardiner \& T. Bennett, unpublished observations) that, in rats receiving prazosin and idazoxan, depressor episodes and tachycardias can be triggered by manual or auditory stimuli. However, it is unlikely that intermittent environmental noises, for example, were entirely responsible for triggering the 'spontaneous' depressor events described here because the latter did not occur simultaneously in animals set up side-by-side in the same laboratory (S.M. Gardiner \& T. Bennett, unpublished observations).

This work was supported by a grant from the British Heart Foundation. We are grateful to Alix Compton for excellent technical assistance and to E. Jarvis for typing the manuscript. Thanks to Professor M. Manning, Pfizer, Reckitt \& Colman, Squibb and ICI plc for their gifts of $\mathrm{d}\left(\mathrm{CH}_{2}\right)_{5} \mathrm{DAVP}$, prazosin, idazoxan, catopril and ICI 118551, respectively.

\section{References}

ARDILL, B.L., FENTEM, P.H. \& WELLARD, M.J. (1967). An electromagnetic pressure generator for testing the frequency response of transducers and catheter systems. J. Physiol., 192, 19-21P.

BENNETT, T., COMPTON, A.M. \& GARDINER, S.M. (1986a). Changes in regional vascular resistance following administration of adrenoceptor antagonists to conscious, unrestrained Long Evans rats. J. Physiol., 381, 18P.

BENNETT, T., COMPTON, A.M. \& GARDINER, S.M. (1987a). Regional haemodynamic responses to prazosin and idazoxan administration in conscious, unrestrained, Brattleboro rats. J. Physiol., 384, 48P.

BENNETT, T., COMPTON, A.M., GARDINER, S.M. (1987b). $\beta_{2}-$ adrenoceptor-mediated vasodilatations in the kidney and hindquarters of conscious, unrestrained, Long Evans rats contribute to the hypotensive effects of $\alpha_{2}$-adrenoceptor antagonism. J. Physiol., 388, 18P.

BENNETT, T. \& GARDINER, S.M. (1987a). In the presence of phenoxybenzamine, peripheral, but not central, administration of idazoxan to conscious, Long Evans rats induces BP instability. J. Physiol., 384, 47P.

BENNETT, T. \& GARDINER, S.M. (1987b). Cardiovascular responses to administration of prazosin and idazoxan in conscious, adrenal demedullated Long Evans rats. $J$. Physiol., 390, 187P.

BENNETT, T., GARDINER, S.M. \& WINN, M.J. (1984). Inhibition of the cardiovascular actions of vasopressin does not cause hypotension in conscious rats treated with an $\alpha_{2}$-adrenoceptor antagonist. J. Physiol., 355, 43P.

BENNETT, T., GARDINER, S.M. \& WINN, M.J. (1986b). The influence of $\beta$-adrenoceptor antagonism on BP following administration of prazosin and idazoxan to conscious,
Long Evans rats. J. Physiol., 377, 60P.

BILSKI, A.J., HALLIDAY, S.E., FITZGERALD, J.D. \& WALE, J.L. (1983). The pharmacology of a $\beta_{2}$-selective adrenoceptor antagonist (ICI 118551). J. Cardiovasc. Pharmacol., 5, 430-437.

BOUVIER, M. \& DE CHAMPLAIN, J. (1983). Selective activation of the adrenal medulla during acute bilateral carotid occlusion and its modulation by $\alpha$-adrenergic receptors in the rat. Can. J. Physiol. Pharmacol., 61, 381-387.

BROOKS, D.P., SHARE, L. \& CROFTON, J.T. (1986). Central adrenergic control of vasopressin release. Neuroendocrinology, 42, 416-420.

BROWN, M.J. \& HARLAND, D. (1984). Evidence for a peripheral component in the sympatholytic effect of clonidine in rats. Br. J. Pharmacol., 83, 657-665.

BROWN, M.J. \& HARLAND, D. (1986). Acute and chronic effects of idazoxan on blood pressure and plasma catecholamine concentrations of rats. Br. J. Pharmacol., 87, Proc. Suppl., 188P.

BURNIER, M., BIOLLAZ, J., BRUNNER, D.B., GAVRAS, H. \& BRUNNER, H.R. (1983). Alpha and beta adrenoceptor blockade in normotensive and deoxycorticosterone (DOC)-hypertensive rats; plasma vasopressin and vasopressin pressor effect. J. Pharmacol. Exp. Ther., 224, 222-227.

CLIFFORD, J.M., FLOCKHART, I.R., HAVIER, M.E., LEWIS, C.J., LLOYUD-JONES, J.G. \& MUIR, N.G. (1983). Metabolism and Pharmacokinetics of Idazoxan (RX 781094). Idazoxan Brochure for Investigators, Reckitt \& Colman.

GARDINER, S.M. \& BENNETT, T. (1981). Baroreflex sensitivity in conscious rats: the influence of recording site. Cardiovasc. Res., 20, 379-383. 
GARDINER, S.M., BENNETT, T. \& KEMP, P.A. (1980). Systemic arterial hypertension in rats expused to shortterm isolation: intra-arterial systolic and diastolic blood pressure and baroreflex sensitivity. Med. Biol., 58, 232239.

GARDINER, S.M., BENNETT, T. \& MACDONALD, I.A. (1986). Withdrawal of salt supplementation from adrenalectomized Wistar rats distinguishes between those animals with, and those without, adrenocortical insufficiency. Clin. Sci., 71, 675-683.

GEDDES, L.A. (1970). The Direct and Indirect Measurement of Blood Pressure. Chicago: Year Book Medical Publishers.

GOERING, J. \& ZIMMERMANN, B.G. (1986). Analysis of adrenoceptor blockade and hypotension elicited by urapidil and prazosin in conscious rat. J. Pharmacol. Exp. Ther., 237, 553-557.

GOMES, C., HENNING, M., PERSSON, B. \& TROLIN, G. (1978). Interaction of $\alpha$ - and $\beta$-adrenergic receptor blocking agents: circulatory effects in the conscious rat. Clin. Exp. Hypertens., 1, 141-165.

HARLAND, D. (1985). $\alpha_{2}$-Adrenoceptors and the control of noradrenaline release from sympathetic nerves in the cardiovascular system of the rat. Ph. D. Thesis, University of London.

HARPER, J.F. (1984). Peritz' F test: basic program of a robust multiple comparison test for statistical and analysis of all differences among means. Comput. Biol. Med., 14, 437445.

KEETON, T.K. \& CAMPBELL, W.B. (1981). The pharmacologic alteration of renin release. Pharmacol. Rev., 31, 81-227.

KNEPEL, W., REIMMANN, W. \& NUTTO, D. (1982). On the mechanisms of the vasopressin-induced inhibition of renin release. Horm. Metab. Res., 14, 157-160.

KOBINGER, W. (1984). New concepts on $\alpha$-adrenoceptors in pharmacology. J. Pharmacol (Paris), 15, suppl. I, 5-22.

LEVITT, B. \& HIEBLE, J.P. (1986). Prejunctional $\alpha_{2}$-adrenoceptors modulate stimulation-evoked norepinephrine release in rabbit lateral saphenous vein. Eur. J. Phar- macol., 132, 197-205.

MCGRATH, J.C. (1982). Evidence for more than one type of postjunctional $\alpha$-receptor. Biochem. Pharmacol., 31, 467484.

MINNEMAN, K.P. (1983). Phenoxybenzamine is more potent in inactivating $\alpha_{1}$ - than $\alpha_{2}$-adrenergic receptor binding sites. Eur. J. Pharmacol., 94, 171-174.

SAWYER, R., WARNOCK, P. \& DOCHERTY, J.R. (1985). Role of vascular $\alpha_{2}$-adrenoceptors as targets for circulating catecholamines in the maintenance of blood pressure in anaesthetized spontaneously hypertensive rats. J. Cardiovasc. Pharmacol., 7, 809-812.

SHARMA, T.R., WAKADE, T.D., MALHOTRA, R.K. \& WAKADE, A.R. (1986). Secretion of catecholamines from the perfused adrenal gland of the rat is not regulated by $\alpha$ adrenoceptors. Eur. J. Pharmacol., 122, 167-172.

SMITH, R.D., TESSMAN, D.K. \& KAPLAN, H.R. (1981). Acute tolerance to prazosin in conscious hypertensive rats: involvement of the renin-angiotensin system. J. Pharmacol. Exp. Ther., 217, 397-405.

SUMMERS, R.H. (1984). Renal $\alpha$ adrenoceptors. Fedn. Proc., 43, 2917-2922.

WAEBER, B., NUSSBERGER, J. \& BRUNNER, H.R. (1983). Blood pressure dependency on vasopressin and angiotensin II in prazosin-treated conscious normotensive rats. $J$. Pharmacol. Exp. Ther., 225, 442-446.

WARNOCK, P. \& DOCHERTY, J.R (1986). Further investigation of the sites of vascular alpha $a_{1}$ and alpha $_{2}$ adrenoceptors in the anaesthetized spontaneously hypertensive rat. J. Cardiovasc. Pharmacol., 8, 67-70.

WINN, M.J. (1985). Factors influencing the control of arterial blood pressure in conscious rats. Ph. D. Thesis, University of Nottingham.

WINN, M.J., GARDINER, S.M. \& BENNETT, T. (1985). Functional involvement of vasopressin in the maintenance of systemic arterial blood pressures after phenoxybenzamine or phentolamine administration, studies in Long Evans and Brattleboro rats. J. Pharmacol. Exp. Ther., 235, 500-505. 